\title{
LA CATEDRAL DE PUEBLA Y JUAN GÓMEZ DE TRASMONTE
}

\author{
P O R \\ EFRAIN CASTRO MORALES
}

I

Z ${ }^{\mathrm{L}}$ año de 1575 se inició la construcción de la catedral nueva de la ciudad de Puebla de los Ángeles. Francisco Becerra trazó el templo y levantó los cimientos, conduciendo la obra durante algunos años con cierta rapidez. Sin embargo, ya para 1599 , se trabajaba en ella muy poco.

Bajo la dirección del maestro mayor Antonio Ortiz del Castillo, durante los primeros años del siglo xvir, la construcción nuevamente progresó. Así, en el año de 1603, los canteros Jerónimo de la Fuente, Pedro de Irazábal, Agustín Garcia Allende, Lorenzo Millán y Juan Romero labraban en "piedra de cantería" los pilares de la obra. 1 Pero esto no era bastante, por lo que el Cabildo Eclesiástico se reunió el 11 de marzo de 1608 para tratar con el Obispo, sobre que se diese "algún remedio a la obra de la iglesia, porque va tan despacio que no se hace nada..."; se discutió además, que mientras la obra no quedara bajo el cuidado y vigilancia directa del Cabildo no habría ningún progreso definitivo. 2

1 Archivo del Venerable Cabildo Angelopolitano: Fábrica Material (1600-1625): "Cuenta que se tomó al contador Juan de Burbua Guevara, Obrero Mayor de la obra de la Catedral de Tlaxcala: f. 20 vta. y ss. En adelante utilizaremos las siglas A.V.C.A., al hacer referencia de este Archivo.

2 A.V.C.A.: Lib. Cabildos: vi: f. 82 vto. 
Dos años más tarde a instancias del mismo cuerpo se expidió una Real Cédula, fechada en Madrid a 8 de febrero y dirigida al Virrey de la Nueva España Marqués de Salinas, en la que se decía “... que la Fábrica y obra de la iglesia nueva de ella está defraudada por causa de ser el obrero a cuyo cargo está, persona secular y favorecido de mis virreyes de esas provincias, que es causa de que se atrevan a traer cmpleados en sus tratos y granjerías más de treinta mil pesos que de ordinario hay sobrados, con que se enriquecen, con gran daño de la dicha obra y fábrica, pues por no deshacerse del caudal que traen entre manos, la dilatan cuanto les es posible y aunque en diversas veces han representado este daño a los dichos mis virreyes, no han puesto hasta agora remedio alguno, y por que el más eficaz juzgan que está al cuidaclo del Obispo y Cabildo de la dicha iglesia, pues como los más interesados darían a la obra toda priesa posible e que se mande que el dicho dinero de la Fábrica esté en una arca de dos llaves, que la una la tenga un prebendado y la otra el dicho obrero mayor, para que con esto no se pueda aprovechar del dinero para sus granjerías..." Se indicaba además la importancia de que la obra se continuase contratándola a destajo y finalmente se ordenaba que se rindiese un informe acerca del estado de la obra, explicando "por qué razón teniendo tanto dinero no está su fábrica adelante y del remedio que se podría poner para la brevedad de ella..." 3 Sin embargo, mucho distaba de ser la solución adecuada para proseguir la obra el hacer informes acerca de lo que ya era sabido por las autoridades reales. Nuevamente el año de 1611 el Cabildo de la Catedral determinó se escribiese al virrey "refrescando lo de la nueva obra". ${ }^{4}$

Las instancias eclesiásticas para que la administración de la obra fuese entregada al Cabildo se vieron pronto confirmadas por un sonado proceso. Don Carlos Buñuelos Cabeza de Vaca, obrero mayor de la Cate(Iral, al rendir sus cuentas de los años de 1609 a 1611, quedó debiendo a los fondos catedralicios la cantidad de 14,985 pesos y 5 granos, comprobándose más tarde que su desfalco ascendía a la suma de 34,100 pesos. Después de un prolongado proceso judicial, que se continuó hasta el año de 1624, la Catedral pudo recuperar alguna parte del dinero desfalcado. 5

3 Ibid., f. I91 vto.

4 Ibid., f. 240 .

5 Archivo Judicial del Estado, Puebla: Expedientes del siglo xrir. 
A pesar de los numerosos problemas administrativos la obra continuaba, pero con gran lentitud; el año de 1615, siendo maestro mayor el destacado arquitecto Mateo Cuadrado y aparejador José de Estrada, se cerraron las bóvedas de las capillas hornacinas, ${ }^{*}$ que concluyó Pedro López Florín, nombrado como maestro mayor en mayo de ese mismo año. ${ }^{7}$

La administración de la construcción continuó en manos de los obreros mayores que designaba el virrey o la Real Audiencia de México, a pesar de las gestiones que realizó el Cabildo y así, durante algunos años, se continuó la obra con realizaciones de escasa importancia, hasta que el 26 de septiembre de 1626 quedó suspendida totalmente, aun cuando todavía se trabajó en algunas pequeñas reparaciones de los talleres. 8

La total suspensión de la construcción dio motivo a algunos intentos por parte del Deán y Cabildo para proseguirla, ante las necesidades crecientes del culto, que la Catedral Vieja no podía cubrir. En octubre de ese mismo año se ordenó al Cabildo hiciese algunas diligencias encaminadas a buscar una persona que tomase a destajo la obra. Los pliegos remitidos por el licenciado Bartolomé Cabrera y Asoca que debian ser entregados al nuevo alcalde para que preparase otro informe acerca de la obra, no recibieron respuesta sino hasta el año de 1630 , a pesar de los mandamientos del Virrey. ${ }^{9}$

En la Real Cédula de 22 de agosto de 1629, otorgada en Madrid, se expuso "... que por tantos años que está comenzada la obra nueva de ella y no proseguirse va recibiendo grandes daños, demás de lo mucho que se gasta en salario de Obrero Mayor y otros oficiales que les va corriendo, sin embargo, de no trabajarse en ella, y que por ser la iglesia vieja muy corta y crecer cada día el número de gentes, es grande la necesidad que hay de acabarse, de más que está en gran peligro de caerse, suplicóme (el Cabildo de la Catedral) atento a ello fuese servido de

6 Vid 1: "Pregones y remates de materiales que se compran para la obra (1615)".

TA.V.C.A.: Fábrica Material (1630-1648): "Autos y carta de pago en virtud del mandamiento del Excmo. Marqués de Cerralvo, virrey desta Nueva España que pagó el Sr. Mariscal de Castilla don Tristán de Luna y Arellano a Pedro López Florín (1633)".

8 Ibid.

A.V.C.A.: Lib. Cabildos: virr: f. 219. 
mandar se prosiga y acabe la obra, y que mientras no se hiciese no lleven salarios las personas que hoy gozan de ellos, y vuelvan y restituyan los que hubiesen llevado todo el tiempo que cesó la obra ... Por lo cual os mando hagais que luego, sin dilación ninguna, se prosiga la obra y porque quiero saber por qué ha estado parada tanto tiempo y en qué se han gastado y consumido los repartimientos que para ello se hicieron, me informaréis muy particularmente sobre ello, y quitaréis luego los salarios a los obreros y demás oficiales, cobrando de ellos los que hubieren llevado el tiempo que han estado ociosos..." ${ }^{10} \mathrm{La}$ comisión designada para hacer las diligencias necesarias acerca de los salarios de la obra recibida por el licenciado Agustín Sedano y el racionero Juan de Ocampo, en el Cabildo celebrado el 10 de enero de 1631. ${ }^{11}$

Sin embargo, la solución fue poco favorable ya que al año siguiente se recibió otra cédula, también otorgada en Madrid a 5 de diciembre de 1631. Se decía que la primera cédula no se había obedecido "a fin de conservar los oficiales y obreros", aumentando los gastos a causa del nombramiento de juez que se hizo a Marcos de Arce "el cual citando partes y a la dicha iglesia, fulmina pleitos y hace informaciones con lo que se dilata el cumplimiento de dicha cédula en daño considerable de mi Real Hacienda..." Ordenando finalmente el virrey que cumpliese con la primera de las cédulas. ${ }^{12}$

En el Cabildo celebrado en 27 de agosto de 1632 se determinó que las órdenes reales se remitiesen al Virrey. ${ }^{13}$ Pero los intentos reales fracasaron y se decidió que, se "guarden en el archivo y contaduría de esta iglesia para que a su tiempo se presenten y pidan su cumplimiento". Esto sucedía ya en el año de 1633. ${ }^{14}$

A pesar de los resultados tan desalentadores el Cabildo Eclasiástico no se arredró y ese mismo año eligió al doctor Juan Rodríguez de León Pinelo, para que fuese a la ciudad de México a suplicar al Virrey, que en virtud de las dos reales cédulas se prosiguiese la obra. ${ }^{15} \mathrm{Al}$ año siguiente informaba que las juntas con el Virrey y el fiscal habían tenido buenos resultados, iniciándose nuevas diligencias para tratar de proseguir la obra. ${ }^{16}$ Ese mismo año se logró un triunfo definitivo con la

10 A.V.C.A.: Lib. Cabildos: Ix: f. 193 vto.

11 Ibid., f. 212 vto.

12 Ibid., f. 291.

13 Ibid, f. 295.

14 lbid., f. 364.

15 Ibid., f. 369.

16 A.V.C.A.: Lib. Cabildos: x: f. 23 vto. 
expedición de otra Real Cédula en la que se ordenó que "ni el Virrey, ni esa Real Audiencia, ni otras ningunas justicias seculares se entremetan a tomar cuentas de la dicha iglesia ... y se deje sólo hacerlo libremente al Prelado y Cabildo, a quienes de derecho y costumbre les toca .. " 17

De esta manera el 9 de agosto de 1634, a causa de las presiones que ejercieron el cuerpo catedralicio y el cabildo civil de la ciudad, el Virrey Marqués de Cerralvo ordenó al alcalde mayor de la Puebla de los Ángeles que le enviase razón de la cantidad de pesos que adeudaban los encomendadores, indios, obreros y alcaldes mayores a la obra, acordándose además que con intervención de dos capitulares de la Catedral, Juan Gómez de Trasmonte, maestro mayor de la Catedral de México, hiciera las condiciones para que la construcción se continuase a destajo. ${ }^{18}$ Un mes después ordenó que todas las personas que quisieran tomar la obra con esta condición comparecieran ante el alcalde Juan de Cervantes Carvajal y los canónigos Agustín Sedano y Juan Rodríguez de León Pinelo. ${ }^{19}$ Fue así como por "voz de Francisco Montejo, pregonero público, en altas e inteligibles voces, habiendo tocado trompetas y chirimías se pregonó el auto susodicho", durante treinta y dos dias.

Por un mandamiento expedido en 23 de diciembre de 1634 se ordenó a Juan Gómez de Trasmonte pasar a la ciudad de Puebla a ver la obra; mandamiento que fue presentado al alcalde mayor el 3 de enero del año siguiente.

Dos días después de ser presentado el documento, Gómez de Trasmonte acompañado por el alcalde y los canónigos, visitó la obra de la catedral y el 10 de ese mismo mes solicitó le fuesen entregadas las plantas que tenía el maestro mayor Pedro López Florín, quien fue notificado ese mismo día. Las entregó de inmediato y le fueron devueltas el día 23, menos algunos papeles que se iban a mostrar al Virrey. ${ }^{20}$

El 18 de enero de 1635, después de trabajar activamente Gómez de Trasmonte se presentó ante el Cabildo de la Catedral "e hizo demostración de una nueva planta que se ha hecho para acabar de todo punto la mitad de dicha iglesia, con sacristía y (sala de) cabildo, para que pueda servir en breve tiempo y conseguirse lo que se pretende, en la

17 Ibid., f. 28 vto.

18 A.V.C.A.: Fábrica Material (1630-1688): "Mandamientos de su Exa. para tomar a destajo la obra desta Santa Iglesia y de las diligencias que en su conformidad se han hecho y remate de los diez y seis arcos torales en noventa mil pesos (1694) ": f. 1 .

19 Ibid., f. 13 vto.

20 Ibid., f. 14 vto. y ss. 
cual enmienda algunos yerros que en la dicha obra se han hallado..." Se acordó que se escribiese al Virrey remitiéndole lo que se había hecho y suplicándole además diese licencia a Gómez de Trasmonte para que pudiera tomar a su cargo la obra de la Catedral poblana, haciendo con él los contratos necesarios. ${ }^{21}$

El arquitecto mostró en el cabildo de la Ciudad, celebrado el día 25, la traza y condiciones que habia ejecutado y poco después partió rumbo a la ciudad de México para entregarlas al Virrey. ${ }^{22}$

Con la aprobación del Marqués de Cerralvo la traza y condiciones estuvieron de vuelta en Puebla, acompañadas de seis edictos que se fijaron en el portal de la Audiencia y en las puertas de la Catedral el 22 de mayo de 1635. Un día después se dictó un auto en el que se ordenó a todos los maestros de albañilería y canterfa se reuniesen la mañana clel día 25. A esta reunión efectuada en la sala capitular acudieron Pedro López Florín, maestro mayor de la Catedral; Juan Diaz Cabañas, arquitecto y alarife de la ciudad; Juan de Hinestrosa, Félix Salcedo, Martín López, Juan Bautista, Jerónimo de la Cruz y Agustín Hernández de Solís, maestros albañiles, los canteros Lorenzo de Adel y Julián de Cárdenas y el albañil Miguel de Castilla, a pesar de que éstos últimos no habían sido notificados. Después de examinar las condiciones y la nueva traza acordaron juntarse el día 31, reunión a la que no concurrieron todos, por lo que se pospuso para el 7 de julio, previa notificación. En esta última reunión se acordó que se harían posturas por escrito y a la mayor brevedad.

Fue hasta el año siguiente, el 12 de febrero, cuando se fijaron los edictos relativos a las posturas para tomar la obra a destajo. Al mes siguiente se presentó la primera; Lorenzo de Adel y Julián de Cárdenas, maestros canteros, solicitaron se les rematase la obra de 16 arcos de cantera, desde la "capilla" de los Reyes hasta el crucero, levantando los pilares seis varas en la parte central, con un costo de 170,000 pesos, para ser terminados en seis años.

Poco después Pedro Garcia Durango, hizo postura para hacer los cerramientos de tres "capillas", desde el altar de los Reyes hasta el crucero, en la nave central, en precio de 60,000 pesos y en un término de seis años.

Otra postura fue la de Martín López y Lorenzo Pérez, maestros de albañilería y vecinos de la ciudad, para hacer dos bóvedas en la sala capitular, en término de un año y con un costo de 22,000 pesos.

21 Vide 16: f. 46.

22 Vide 18: f. 25. 
Jerónimo de la Cruz, ofreció concluir las dos bóvedas que componian la sacristía, en un precio también de 22,000 pesos.

El 23 de junio se efectuó un auto en el que Lorenzo de Adel y Julián de Cárdenas hicieron baja en su postura de 170,000 pesos a 90,000. Al año siguiente el Virrey expidió un nuevo mandamiento para que se pregonase esta postura, durante 30 días, tanto en la ciudad de Puebla, como en la de México y, si no era mejorada, se les rematase.

De esta manera el día 20 de abril de 1637 "estando en los portales de la Audiencia Ordinaria, a las 11 de la mañana y dando las 12 no se' mejoró la postura, se remató la obra de los 16 arcos torales en 90,000 pesos a Lorenzo de Adel y a Julián de Cárdenas, guardando las condiciones..." 23

\section{III}

Juan Gómez de Trasmonte, maestro mayor de la Catedral de México desde el año cle $1630,{ }^{24}$ pasó a Puebla para "ver si lo fabricado de la iglesia nueva della está conforme a buena obra o si tiene algún defecto que requiera enmienda, y si los informes del alcalde mayor y Cabildo Eclesiástico que han hecho del modo y materiales con que se ha de proseguir, es conforme a obras de arquitectura, y haga las condiciones $y$ lo demás del modo que se ha de acabar". ${ }^{25}$

El año de 1634, en presencia de los capitulares de la Catedral y del alcalde mayor de la ciudad procedió a reconocer la obra tantos años suspendida, encontrándose que estaba "bien acondicionada, sin demostración alguna de sentimiento, las paredes y pilares son de bastante grueso y suficiencia para recibir las bóvedas y no es de mucha consideración lo que se ha de enmendar en lo hecho..."

Observó además que las capillas hornacinas "que son catorce, estén cerradas de bóveda de ladrillo y sólo les falta enladrillar las azoteas y blanquear y lucirlas por debajo..." La sacristía y la sala capitular carecían aun de bóveda, sugiriendo que sería más adecuado cubrirlas con "piedra laja" por ser "bien a propósito y de menos costo este material sin comparación que de cantería, como estaba dispuesto..." La bóveda

23 Ibid., f. 31 vto. y ss.

24 Berlin, Heinrich. Artifices de la Catedral de México. Anales del Instituto de Investigaciones Estéticas. Vol. 1II. Núm. 11. Méxíco, 1944, p. 28.

25 Ibid. 
del altar de los Reyes - nos dice- "está en altura de cerrar... que también será de piedra laja y ladrillo como todas las demás de las tres naves"; sin embargo, había una cornisa de seis pies de vuelo "la cual va orlando y dando vuelta, y en el mismo testero del altar, cosa bien fuera de traza" que debería ser quitada "por ser obra mal dispuesta, reprobada y fuera de su lugar, de más de que los grandes vuelos de una parte y otra asombran y quitan luz de hermosura a el edificio, y si se hubiera de continuar será mucha la costa, como estaba dispuesto por las trazas de los maestros desta obra..."

Para abreviar la obra, nos dice en su parecer, que convendría trabajar para cubrir las naves desde el crucero, exclusive, al altar de los Reyes "y no más, levantado el edificio y acabándole en toda perfección" para que en esa parte, ya cubierta de bóveda se pudieran celebrar los oficios divinos "con mucha decencia"; calculaba un costo para esta obra de 270,000 pesos, siendo factible concluirla en un lapso de 5 años.

Pero para lograr esto, el Virrey debería otorgar un mandamiento por el que acudiesen a trabajar en la obra los indios, tanto peones como oficiales, de los contornos de la ciudad, como ya lo habian hecho, "aunque sean menos por causa de la mortandad, que otros se buscarán pues aun pagándoles a precio aventajado no se hallan".

El mandamiento virreinal se debería hacer extensivo a los peones y oficiales indigenas que trabajaban en otras obras, debiéndolas abandonar para trabajar en la Catedral "como obra real". También por espacio de un año no se debería permitir poner en almoneda ninguna obra importante "porque de otra manera subirian de precio los materiales y no se podría conseguir este negocio que es de tanta importancia, en que su Magestad gasta tan grande suma de ducados".

Al proseguirse la obra debería ser aprovechado el material que se encontraba ya dispuesto. De esta manera, para cerrar la sacristía que iba a ser de "moldura costosa al modo de las de México", esto es de traceria, había algunas piedras labradas, que eran "en número de 74 y de otro género de molduras hay 5 claves, 83 piezas de capital, 92 piedras de cornisa, 31 piedras redondas, 71 sillares labrados, 113 sillares por labrar, de ventanas 26 piezas, una canal y 2 pasos de caracol y 7,000 ladrillos, en ser que sobraron de las capillas hornacinas y no hay materiales dentro de la obra". Este material sobrante podría ser acomodado en otras partes del edificio.

Informó asimismo que la ciudad contaba con materiales de construcción de buena calidad, tanto de cantera para los arcos como de piedra 
laja para las bóvedas; por lo demás el "ladrillo es mejor que el de México, la cal no es tan buena, pero hace su efecto". También era una ventaja las cercanías de las canteras "casi dentro del lugar y lo menos el ladrillo", a pesar de que "con todo esto vale hoy un millar de ladrillos ordinarios doce pesos. La cal a cuatro pesos el caiz. Una carretada de piedra laja dos pesos, que viene a ser menos un tercio de los que es braza en México, según lo cual casi tiene la mesma costa. La piedra de cantería vale tres pesos la carretada y trae como media la de México, más desbastada y es más dura, con que viene a ser una la costa y lo mesmo es la arena..."

Después de su parecer y opinión acerca de lo hecho y de los materiales con que se contaba, procedió a disponer las nuevas condiciones bajo de las cuales debería ser proseguida la obra.

En primer 'ugar, la sacristia y la sala capitular deberían cubrirse "de bóveda de piedra laja y ladrillo, acabando para ello las formas de cantería como están empezadas, en correspondencia de los arcos que están acabados en dichas piezas, quitando los xarxamentos (sic) de los rincones y moviendo el cerramiento de arista llano y liso, que no toque a regla por las formas, como suele hacerse, más antes suba de punto una tercia por sima (encima) de ella y para su ornato se dispondrán unas fajat compartidas en los intervalos que resultan de las diagonales, de cuatro dedos de relieve, al modo de lo que está ejecutado en la iglesia de San Agustín de esta ciudad, que envestido y lucido como ello de yeso dará el mejor agrado que comúnmente tiene este género de obra. Para lo cual entre la piedra laja de que se han de cerrar estas bóvedas se pondrá ladrillo en las partes convenientes, de manera que hagan labor". La piedra que se utilizaria en estas bóvedas debería de tener "por lo menos de media vara arriba del peralte, de ancho una tercia y de canto una sesma poco más"; debería ir sin labrar, importando que algunas fuesen mayores que otras, para lograr de esta manera "trabazón y ligazón", dejando además dentro de la bóveda cinco cañoncitos de barro cocido de "cuatro dedos de hueco, uno en el medio y cuatro a los lados" para poder colocar colgaduras, efectuar reparaciones, limpieza y otros usos.

La bóveda del altar de los Reyes debería construirse de ladrillo y piedra laja, con correspondencia a la altura de la nave central, "de género vaida", para lo cual se tendría que quitar la cornisa antes mencionada y "acabar de subir e igualar sus formas y ventanas, sobre que se ha de cargar, y se enlucirá de yeso formando unos compartimientos a trechos, 
debidos y según arte, que den relieve un sesma y esto sin moldura, por que la distancia de la vista no la percibe"; debían estar hechos a base de fajas entrelazadas como ya lo había indicado en la obra de la sacristía y sala capitular.

Desde esta bóveda hasta el crucero también se harían las bóvedas de ladrillo y laja "para lo cual se han de encapitelar los pilares torales... de manera que las medias formas que corresponden a la nave mayor se han de levantar sobrepujando a las colaterales". El peralte de la rosca de los arcos tendría el relieve de la media muestra, con la advertencia de que los arcos de la nave central deberían ser auxiliados con unos sobrearcos de "piedra laja crecida" incluidos dentro de la bóveda.

Para cerrar las naves laterales "sobre los arcos perpianos, que son los de las capillas hornacinas, se han de levantar sus formas de medio punto correspondientes a las de las naves colaterales, cuya pared debe tener el mismo grueso de los dichos arcos perpianos sobre que cargan y enmedio de cada una de ellas se ha de hacer una ventana de cantería, rasgada, de dos varas de ancho y tres y una tercia de alto". Sobre las paredes divisorias de las capillas hornacinas se deberian colocar arbotantes hechos de laja, excepto en las esquinas, remates y cornisamento, que serían de cantera, para servir de estribos a las naves laterales y conducir el desagüe de las bóvedas hasta las canales de las capillas.

Los cerramientos de las tres naves, central y laterales, deberían ser "de género vaido", utilizando laja y ladrillo en la forma siguiente: "los dos tercios del diámetro de cada bóveda se levantarán de piedra laja y el último de ladrillo mayor que el ordinario, y así tendrán una cuarta de ancho, de largo una tercia y tres dedos, de forma que la rosca de la bóveda en la nave mayor será de dos ladrillos, con que tendrán de gruesos poco más de tres cuartas ..." Las mezclas serian de materiales escogidos, arena cernida y ladrillo picado, dejando en cada bóveda cañoncitos de barro para las lámparas y limpieza. En las enjutas y "senos" de las bóvedas no se colocarian cántaros para quitar peso ya que ésto es de los antiguos y no tan aprobado", sino se construiría en los ángulos otra pequeña bóveda.

En las uniones de las naves laterales con la principal se deberian colocar sobrearcos de cantera embebidos en las bóvedas, para fortalecerlas y recibir el peso de la nave central, poniendo además sus arbotantes "que les sirven de estribo y reciben las aguas lluvias". Sus azoteas se cubrirán de ladrillo "dejando descubierta y esenta (sic) Ia corona 
de cada bóveda una tercia parte de su diámetro, esto es por conveniencia de hermosura y menos peso". Finalmente su interior se enluciría con yeso, haciendo la misma decoración antes mencionada.

Encima de la cornisa de las capillas hornacinas se había construido un antepecho "de una vara de grueso y vara y media de alto" que resultaba desproporcionado, siendo conveniente desbaratarlo y hacer otro de dimensiones menores, con una moldura "mediana" por la parte de afuera. En la parte exterior, sobre el cornisamento de la nave central se haría otro antepecho "que sirva de contrapeso a la cornisa, remate y ornato al edificio".

Los estribos "que acompañan los pórticos del crucero por la parte exterior" tenían una cornisa a nivel de las capillas laterales que estorbaba el adorno de las portadas, por lo que deberia ser sustituida por una imposta "de vuelo recogido", disminuyendo sobre ella dichos estribos "una ochava de cada lado, cuyo movimiento dará principio con otra media caña".

Finalizaba sus condiciones Gómez de Trasmonte especificando que "las mezclas para fabricar toda esta obra se harán de manera que a dos medidas de arena corresponda una de cal y para las bóvedas y cantería irá cernida la arena, cuidando de su mixtura y repasandola de una parte a otra, que esté algún tiempo detenida y amontonada, se le irá echando agua y repasandola juntamente para se vaya incorporando y traspasando la humedad, que ésto llaman deretido, con lo cual cuando se venga a batir la mezcla echándole más agua para ello hará mejor efecto en la obra".

A pesar de las condiciones bien especificadas fue de opinión que clurante la construcción la obra debería ser visitada cada cuatro meses "por personas de inteligencia" para resolver las dudas que fuesen surgiendo, y que debería nombrar el Virrey.

Después de leerse las condiciones, en el Cabildo se reparó en que no se habia señalado el sitio del coro provisional y la opinión fue que se debería instalar en el crucero, como ya lo había marcado en una de las plantas, cerrando las tres naves con muros provisionales, para que se instalasen en el crucero la sillería y rejas de la Catedral Vieja, utilizando pilares de madera para soportar un techo provisional asimismo de madera. Finalmente, mientras no se acabase la obra las naves se reforzarian colocando estribos que reciban sus arcos, "encadenados con unas planchas y tornapuntas". Una de las torres debería edificarse hasta 
el cuerpo donde se pudiesen colocar las campanas "dejando to demás, que se irá prosiguiendo con el resto del edificio". ${ }^{20}$

Las condiciones que realizó Gómez de Trasmonte, para que la obra se concluyese hasta el punto en que pudiese servir inmediatamente para el culto, dejan algunos puntos sin aclarar. Sin embargo, parece que por "apuntamientos" posteriores precisó algunas de las condiciones para concluir el edificio sobre el plan que se esbozó al principio.

Según el parecer y condiciones de Gómez de Trasmonte, otro arquitecto - quizá Pedro García Ferrer- redactó algún tiempo después varias condiciones que se deberían seguir para terminar la construcción de la cúpula que cubriría el crucero.

En primer lugar se deberían cerrar todas las bóvedas "en contorno de hacer la media naranja". Las pechinas de ella se fabricarían "con sus tiranteces en las juntas, imitando las de cantería, por que de otra manera no harán el efecto conveniente, ni quedarán firmes"; las hiladas no deberían cargar sobre las juntas de las otras "porque de no tener cuidado con esto aunque se siga la traza que se da en una obra, suele hacer vicio un edificio".

Los estribos que se colocasen encima de la media naranja "para el ventanaje que se hubiera de hacer, se hagan con tanto cuidado en la trabazón excusando demasiado macizos por quitar peso"; también el cornisamento interior que descansaría sobre las pechinas se deberia hacer de ladrillo para quitar peso.

Respecto a las pechinas se señaló que, "se pongan en su lugar sin levantarlas sobre las roscas de la bóveda, siguiendo las cuatro formas de cantería sin levantarlas sobre dichas roscas y que no se salga del arte por la fealdad que tendrá y por la costa y peso que se excusa". ${ }^{27}$

Las gestiones del Cabildo Eclesiástico que concluyeron en la elaboración de las condiciones de Gómez de Trasmonte y en el remate de la obra a los maestros canteros para que se prosiguiese a destajo, fracasa-

26 Vide 18.: f. 26 y ss.

27 A.V.C.A.: Fábrica Material (1704-1775): 1. 
ron, y es difícil precisar las causas por las cuales el expediente fue cerrado, sin que la construcción fuese proseguida, pero es de creerse que fueron poderosos motivos de carácter económico y administrativo.

La "Catedral de Plata" como era llamada la obra tantos años inconclusa y que tantos desembolsos causaba al erario real muy pronto se vio reanudada.

La llegada del gran Obispo Juan de Palafox y Mendoza cristalizó los esfuerzos de los Cabildos Eclesiásticos y Civil. Por la Real Cédula de Felipe IV de 19 de enero de 1640 se le encargó prosiguiese y concluyese la obra de la catedral, orden que tomó con verdadera pasión.

Pocas semanas después de su llegada a Puebla el día 7 de agosto mandó que se hiciese un auto para que la obra saliese en pregón para ser rematada total o parcialmente. Cuatro días después fue visitada la construcción por el maestro mayor y otros empleados "teniendo a la vista el auto proveído por el excelentísimo señor Virrey Marqués de Cerralvo, en orden de alterar y variar la primera planta" y el 13 de ese mismo mes la obra fue reanudada sin interrupción hasta el 18 de abril de 1648 en que se consagró. 28

La participación de Juan Gómez de Trasmonte, en la historia arquitectónica del templo máximo de Puebla, tiene una gran importancia.

En la traza inicial se introducen modificaciones en la técnica empleada para cerrar las bóvedas. Cabe mencionar sin embargo, que el cerramiento de las capillas hornacinas había sido ya modificado, pues no se habían cubierto con bóvedas de tracería, sino ya estaban cerradas con bóvedas de arista, fabricadas de ladrillo, modificación que bien pudo haber sido introducida por Mateo Cuadrado o Pedro López Florín, a quien se menciona como autor de una traza.

La Sala Capitular y particularmente la sacristía, para la que ya se encontraba labrada cierta cantidad de piedra, quedaban cubiertas originalmente con "moldura costosa al modo de las de México" o sea con nervaduras, cerramiento que fue modificado por bóvedas de arista hechas a base de piedra laja y ladrillo.

La bóveda del Altar de los Reyes sufrió modificaciones más impor-

28 Fernández de Echeverria y Veytia. Historia de la fundación de la Ciudad de la Puebla de los Ángeles en la Nueva España, t. 11, p. 65. 
tantes, como fue quitar una cornisa y elevarla en correspondencia con el resto de la nave central. Como restos de su primitiva disposición se conservan dos repisas a nivel de las capillas hornacinas que marcan la altura que iba a tener el cerramiento inicial de todo el templo, aun cuando parece que ya no datan del siglo xvi sino de una época más posterior.

Según las trazas de Pedro López Florín y otros maestros, las naves deberían ser cubiertas "a un peso y movimiento", sin crucero ni cimborrio. Al decir del Obispo Palafox, la obra iba errada "porque siendo cinco naves con las capillas, iban las tres principales a un peso, con que quedaba baja, oscura y desproporcionada. Por esto se alzó la nave mayor sobre las colaterales y cada una recibe luces de sí misma; con que queda alta, clara, hermosa y proporcionada". 29

Hay que señalar que además de la obra de la Catedral de México, influyó en las modificaciones el elevado costo de la piedra labrada de los cerramientos con nervaduras, así como también la premura con que debería ser concluída la obra, como lo señaló nuestro arquitecto al decir que en su traza "enmienda algunos yerros que en la dicha obra se han hallado, mudándola en el estado que hoy tiene y en cubrir las bóvedas y hacer otras cosas a lo moderno, no usando en esto la antigua planta, por ser obra de mucha más costa y de dilación de tiempo y muy tosca y a lo antiguo...". ${ }^{30}$

La modificación que eleva las naves sobre las capillas hornacinas haciendo que tenga "de alto la nave mayor ochenta y seis pies y la colateral sesenta (esto es desde la superficie del suelo natural hasta la vértice del arco)", así como la distribución de las bóvedas en el crucero en que iría la cúpula mayor o central, siguen el sistema utilizado en la catedral de la ciudad de México. Hay que hacer notar que "el trozo de arquitrabe que se interpone en las naves procesionales, entre el capitel y el arco es, tal vez, testimonio del momento en que se pensaba cubrir las tres naves a igual altura, siguiendo el sistema que se mantuvo en Guadalajara". ${ }^{31}$

Queda fuera de duda que las condiciones y dictámenes dados por Juan Gómez de Trasmonte fueron utilizados para modificar de una

29 Carta del Venerable Obispo de Puebla don Juan de Palafox y Mendoza al Rey don Felipe IV, en 19 de mayo de 1646. Publicada en "La Puebla de los Angeles en el sigla xviı", México, 1945, p. 150.

30 Vide 21.

31 Angulo Iñiguez, Diego. Historia del Arte Hispanoamericano. t. I, p. 429. 
manera decisiva la estructura de la Catedral poblana. Es posible que no se hayan seguido punto por punto estos lineamientos, sino que fueron modificados por otros arquitectos que participaron en la obra, como García Ferrer. Sin embargo, son la base e inspiración para variar el sistema constructivo hasta entonces emprendido para dar cima a una obra que, después de años y años, sería el máximo esplendor de la arquitectura colonial en el valle poblano-tlaxcalteca. 